\title{
LAS ORTOGRAFIAS DE MAYANS Y BORDAZAR: EL FONDO DE UNA POLÉMICA
}

\author{
Marí José Martínez Alcalde \\ Universidad de Valencia
}

En 1730 se publicó la segunda edición de la Ortografía Española del inpresor valenciano Antonio Bordazar de Artazú ${ }^{1}$. El tratado fue en principio uno más entre los muchos que aparecieron a lo largo del siglo ${ }^{2}$, incluso después de la publicación de la primera Ortografía académica de 1741. Sin embargo, la obra ha merecido una atención particular por una cuestión en granparte ajena a su contenido doctrinal y relacionada, en cambio, con una de las características del ambiente cultural de nuestro siglo xviri. Se trata de la polémica desatada en torno a la autoria de la obra, en la que intervinieron de forma activa personajes como Mañer y que enfrentó a dos de las figuras principales de aquel siglo: Feijoo y Mayans.

La historia de este enfrentamiento ha sido abordada por J. A. Tamayo y por A. Millares Carlo en sendos artículos aparecidos en la Revista de Filologia Española hace ya algunos años ${ }^{3}$, y más recientemente por Antonio Mestre $^{4}$ y Vicente Peset ${ }^{5}$. Se puede conocer así con detalle el desarrollo

1 Antonio Bordazar de Artazú, Ortografía Española fijamente ajustada a la naturaleza invariable de cada una de las Letras. Segunda impressión, en que se añade una Apologia, Valencią, Imprenta del autor, 1730. La primera edición se publicó en 1728, también en Valencia. Citaremos por la edición de 1730, como Ortografía Española.

2 El número de tratados se aproxima a los 50 . Cf. Conde de la Viñaza, Biblioteca Histórica de la Filología Castellana, tomo II, Madrid, 1893. A. Esteve Serrano, Estudios de tcoría ortográfica del español, Murcia, 1982.

3 A. Millares Carlo, "Feijoo y Mayans", Revista de Filología Española, X, 1923, págs. 93-120. J. A. Tamayo, "Mayans y la Ortografía de Bordazar"; ibíd., XXV, 1941, págs. 205-225.

4 Antonio Mestre, "Divergencias entre ilustrados: el caso Feijoo-Mayans" y "Correspondencia Feijoo-Mayans en el Colegio del Patriarca", en El mundo intelectual de Mayans, Valencia, Publicaciones del Ayuntamiento de Oliva, 1978, págs. 123-200.

5 V. Peset Llorca, "Feijoo y Mayans", en Gregori Mayans i la cultura de la Il.lustració, Barcelona-Valencia, Curial-Tres i Quatre, 1975, págs. 393-428. 
epistolar de una polémica limitada en el tiempo, pero que estuvo presente siempre en la hostilidad entre Mayans y Feijoo, cuya oposición, como ha puesto de relieve A. Mestre ${ }^{6}$, va más allá de lo personal para afectar a dos concepciones contrapuestas sobre la reforma de las letras españolas.

Resumiremos brevemente el episodio. La primera edición de la Ortografía de Bordazar apareció en 1728; Mayans, amigo personal del autor, supervisó la realización de la obra y la difundió entre sus numerosos corresponsales, alabándola y señalando que era, salvo ligeras diferencias, coincidente con su propio sistema. La obra provocó un comentario contrario por parte de Mañer, autor a su vez de otro tratado ortográfico ${ }^{7}$. En 1730, Bordazar publicó una segunda edición a la que añadió una "Apología" en la que se defendía de los ataques de Mañer, y una carta de Feijoo en la que éste se manifestaba de acuerdo con su sistema. Poco después, Mañer hizo pública otra carta privada de Feijoo a Pardo de Figueroa en la que el benedictino afirmaba que Mayans le había manifestado ser el autor de la $\mathrm{Or}$ tografía publicada por Bordazar, confirmando así lo que al parecer era un rumor en determinados círculos ${ }^{8}$. Mayans reiteró en su correspondencia con diversos interlocutores la falsedad de lo afirmado por Feijoo, y exigió a éste la retractación en dos cartas, una española y otra latina. Efectivamente, Feijoo reconoció su error en otra carta y criticó duramente, como lo había hecho el propio Mayans, la indiscreción de Mañer. Mayans, poco aficionado a escándalos y polémicas ${ }^{\theta}$, dio ésta por zanjada, aunque nunca la olvidó y mantuvo siempre en privado su reticencia hacia las obras del benedictino. Incluso muchos años después, relató los detalles de esta historia a algunos de sus corresponsales ${ }^{10}$, reiterando siempre la autoria de Bordazar y las discrepancias de la obra con su propio sistema ortográfico.

6 Antonio Mestre, Despotismo e Ilustración en España, Barcelona, Ariel, 1976, especialmente págs. 28-36. Vid. supra, nota 4.

7 Salvador José Mafier, Méthodo Breve de Ortographia Castellana, Córdoba, 1925. Segunda edición en Madrid, 1730.

8 Bordazar a Mayans (14-VII-1728): "Lo que me envanece más, es lo de hacerle a U. M. digno autor de la Ortografía, que aunque no se engañan del todo, me paladeo viéndome decente intérprete de quien tengo por dueño, i por oráculo; i tendré a bien que agradase a los buenos, aunque sean los menos." Biblioteca Archivo Hispano Mayansiana (BAHM), 2, Colegio de Corpus Christi, Valencia.

- Mayans a Fray Bernardo de Ribera (10-II-1753): "Los ignorantes no podrían prevalecer si, como los sabios son superiores a ellos en la ciencia, lo fueran en la autoridad. Por esso me indigno yo de que siendo tan pocos los que saben, vivan tan desunidos, desacreditándose unos a otros" (BAHM, 151).

10 Sólo como ejemplo: en el año 1750 y 1753 relata la polémica en sendas cartas al Conde del Águila y a Diego de Arredondo, respectivamente (BAHM, 148 y 116). También repite la historia en el Specimen Bibliothecae Hispano Majansianae (Hannoverae, 1753) y en la Gregorii Maiansii, Generosi Valentini, Vita (Wolfenbutelae, 1756), obra 
La información sobre los datos históricos de la polémica y la publicación de las principales cartas en las que se plasmó han centrado hasta ahora la atención de los autores que se han ocupado del tema, interesados sobre todo en la peripecia del enfrentamiento personal entre dos grandes figuras ${ }^{11}$, asi como en ofrecer una muestra representativa de lo que fue el ambiente intelectual del xvin español. No se ha abordado, sin embargo, lo que constituye el fondo de la cuestión y a lo que Mayans aludió repetidamente como prueba que zanjaría cualquier especulación. Se trata, evidentemente, del cotejo de su propio sistema ortográfico con el expuesto por Bordazar.

Cuando la malintencionada indiscreción de Mañer hizo saltar la polémica sobre la obra del impresor, Mayans negó repetidamente su autoria, sin ocultar el apoyo y la colaboración que había prestado a Bordazar en la elaboración de la obra. Ésta habría tenido como origen una conversación de ambos sobre el tema y el posterior préstamo de algunos tratados de ortografía por parte de Mayans para que Bordazar ampliara sus conocimientos ${ }^{12}$. Insistió don Gregorio en que las ideas expuestas finalmente fueron obra de Bordazar y que incluso había discrepancias entre sus respectivos métodos, llegando a ofrecer a Mañer el suyo, inédito, para que pudiera compararlos ${ }^{13}$.

Efectivamente, el hecho de que el tratado ortográfico de Mayans fuera entonces, como hoy, inédito, hizo imposible comprobar en su momento sus afirmaciones sobre discrepancias concretas. El Abecé Español nunca se pu-

de Mayans que apareció a nombre de Strodtmann. Citaremos esta última obra según la edición de Antonio Mestre en Valencia, Publicaciones del Ayuntamiento de Oliva, 1974.

11 "El espectáculo del disentimiento entre dos grandes varones excitó por lo común la curiosidad de quienes gustaban de verles contender poniendo su ciencia al servicio de la pasión humana." J. A. Tamayo, art. cit., pág. 205.

12 Mayans al Conde del Aguila (2-V-1750): "Antonio Bordazar que fue mi impressor, me pidió le esplicasse la razón de mi Ortografía; le di gusto en una conversación; i como era hombre de gran juicio, fue a su casa i puso por escrito todo lo que yo le había dicho, mostrándomelo después; i aviéndome parecido bien, me pidió licencia para reimprimirlo. Le dige que para egecutarlo mejor, podia ver algunas ortografías, como la de Mateo Alemán, Gonzalo Correas i otras pocas, que le presté..." (BAHM, 148). Tamayo reproduce esta carta según un manuscrito de su propiedad que no sigue la ortografía del autógrafo de Mayans y presenta ligeras variaciones respecto a éste. Cf. J. A. Tamayo. art. cit., págs. 210-213. En la Vita, ed. cit., págs. 42-43, Mayans cuenta el episodio del mismo modo, añadiendo únicamente algún detalle.

13 Mayans a D. Mercurio López Pacheco, Marqués de Villena (7-XI-1731): "Suplico a U. M. que, pues profesa amistad con D. Salvador Mañer, le asegure mi candidez, que por más que diga, i haga contra mí, no me daré por ofendido, pues procuraré anteponer las obligaciones de la caridad cristiana a los vanagloriosos estímulos del propio amor. I soi de ánimo tan generoso, que si quiere que le exponga mi sistema ortográfico le obedeceré con gusto, con tal que me trate con decoro, i sin gravar su conciencia" (BAHM, 138). El mismo párrafo aparece en una carta a D. Josef Pardo de Figueroa, $\sin$ fecha (ibid.). 
blicó, aunque Mayans siempre deseó hacerlo. En 1735 tuvo oportunidad de exponer un resumen de sus ideas sobre el tema en las Reflecciones que acompañan su edición de las Reglas de Ortografía de Nebrija ${ }^{14}$. La polémica, sin embargo, quedaba ya lejana y a nadie pareció interesarle el cotejo con la obra de Bordazar.

La principal dificultad a la hora de realizar una comparación entre los sistemas de Mayans y de Bordazar radica en la falta de fechación de los textos que componen el manuscrito inédito que bajo el título Abecé Español se conserva en la Biblioteca del Colegio de Corpus Christi de Valencia ${ }^{15}$. Si hemos de atender a la afirmación que Mayans realiza en la "Dedicatoria a Patiño" de su edición, en 1735, de las Reglas de Ortografía de Nebrija, su Abecé estaría ya elaborado en $1723^{16}$. En la carta latina, a la que ya nos hemos referido, en que exigía a Feijoo una retractación, señala que cuando expuso su método a Bordazar ya había escrito un librito sobre el asunto ${ }^{17}$. Sin embargo, cuando en 1728 se dirige al Marqués de Villena ${ }^{18}$ para enviarle la obra del impresor manifiesta que él mismo tenía apuntado algo sobre el tema, pero advierte: "Antes de resolverme de echar el cuerpo al aire, deseo ver cómo se recibe en España este Sistema Ortográfico."

El Abecé inédito al que nos estamos refiriendo recoge en realidad cuatro manuscritos diferenciados, ninguno de los cuales ofrece información explicita en cuanto a su fecha de composición. El primero de ellos, el más extenso, parece ser propiamente el Abecé, y como tal está encabezado, presentando una obra, al parecer, completa. El segundo, por el contrario, tiene un carácter evidentemente fragmentario: sigue el orden del alfabeto en el estudio de las grafías y se interrumpe al llegar a la $\mathrm{H}$. En cuanto al tercer manuscrito,

\footnotetext{
14 Gregorio Mayans y Siscar, Reglas de Ortografía en la lengua castellana compuestas por el Maestro Antonio de Lebrija. Hizolas reimprimir añadiendo algunas Reflecciones don Gregorio Mayans i Siscar, Valencia, Benito Monfort, 1765. Primera impresión en Madrid, 1735.

15 Se trata de un volumen en cuarto con 89 páginas numeradas seguidas de 36 sin numerar, manuscrito con letra de don Gregorio y con anotaciones en los márgenes. Entre los diferentes textos hay páginas en blanco.

16 "Tuve tentación de añadir unas notas en todos los lugares que pidiessen alguna mayor claridad, pero por no escrivir dos veces unas mismas cosas, reservé aquellas noticias para quando quiera U. E. que llegue el caso de que yo publiqué mi Abecé Español. Obra que tengo trabajada años ha, pues ha más de doce que la comuniqué manuscrita a mi estrechíssimo amigo don Francisco Galiano Espuche" (op. cit., pág. xrv).

17 Relatando cómo Bordazar le pidió que le expusiese su sistema ortográfico, escribe Mayans: "Respondi libellum scripsise me de illo argumento; necessarium tamen non esse ad eum recurrere (eramus tunc in appidulo vulgo Pavias animi recreandi caussa) satis esse paucis verbis meum proponere systema, ut vera ella agnosceret, quas ipse dixeram." Apud V. Peset, op. cit., pág. 414.

18 Mayans al Marqués de Villena, 15-VI-1728 (BAHM, 115).
} 
parece tratarse de una larga carta a un desconocido personaje al que da el tratamiento de U. Ex. ${ }^{18} \mathrm{y}$ se interrumpe en la exposición final sobre los signos de puntuación o distinciones, lo que remite también a un texto no completado. El cuarto y último manuscrito es el más breve: apenas tres páginas que recogen, en forma de notas apresuradas, descripciones articulatorias de las vocales y de las consonantes labiales.

Dejando aparte este último, los tres manuscritos ofrecen las mismas ideas con alguna ligera variación, y una mayor o menor extensión en las explicaciones y en el aporte de datos. Lo que varia en cada caso es el método, la forma de exposición. La del primer manuscrito es más amplia y erudita. Propone en él su Cartilla por medio de un cuadro que, con ligeras variaciones, recoge en las Reflecciones ${ }^{20} \mathrm{y}$ desarrolla un verdadero método ortográfico. En el segundo, la exposición es más breve y pedagógica; mientras que en el tercero sólo se refiere con amplitud a las grafías conflictivas, y tiene un tono más narrativo y menos sistemático.

En cuanto a la posible fechación, algunos datos permiten aventurarla de forma amplia. Una cita literal del "Discurso Proemial de la Ortographia" del Diccionario de Autoridades (1726) que aparece en el primero de los manuscritos, proporciona la primera referencia: no es ésta la redacción de 1723 a la que nos hemos referido anteriormente. Hay en este mismo manuscrito una alusión a Bordazar como ortógrafo, lo que situaría su redacción en una fecha igual o posterior a 1728. La referencia a cierta opinión de Feijoo sobre el caos de la ortografía que aparece en el segundo tomo de su Teatro Crítico ${ }^{21}$, también mencionada por Bordazar en su obra ${ }^{22}$, apoya esta hipótesis. Existe, además, en el texto, una alusión de Mayans a la ortografía de Feijoo basada en las cartas que éste le ha dirigido, y la correspondencia entre ambos autores no comenzó hasta $1728^{23}$. Ya hemos señalado, por otra parte, que en la carta que en junio de ese mismo año dirigió al Marqués de

19 La frase en que aparece el tratamiento y la referencia al carácter de carta se encuentra tachada, aunque legible, en el manuscrito.

20 El cuadro que aparece en las págs. 82-84 de la Reflecciones repite el de las páginas 47-48 del Abecé (primer manuscrito) con ligeras variaciones. La H, por ejemplo, no recibe numeración en 1735 y sí en el Abecé; sin embargo, en éste sí aparece la K, que no se recoge en las Reflecciones.

21 "En quanto à la ortographía (pues también de esto suele dar razón el Autor à los lectores) no sigo regla determinada, porque no la hai. Unos quieren que se arregle a la etymologia, otros à la pronunciacion; i ni unos, ni otros cumplen con el mismo precepto que prescriben: pues no se hallarà Autor alguno que siga en todo la etymologia, ò que siga en toda la pronunciacion." Feijoo, Prólogo al tomo II del Teatro Crítico, Madrid, Imprenta de Francisco del Hierro, 1728.

22 Ed. cit., pág. 5 .

23 Vid. supra, notas 4 y 5 . 
Villena indica que sólo tiene algunos apuntes sobre el tema, aunque según la carta latina a Feijoo que hemos citado más arriba, su tratado ya estaba escrito cuando expuso a Bordazar su sistema ${ }^{24}$. En otras cartas sobre la polémica manifiesta también que su propio método, el $A b e c e ́$, está listo para ser consultado y publicado cuando encuentre el apoyo suficiente, y lo reitera en escritos de años posteriores. En todo caso, podemos señalar que en el momento de la redacción Mayans no conocía las Reglas de Nebrija, que publicó en 1735 y a las que tuvo acceso siendo bibliotecario en Madrid, cargo que desempeñó entre 1733 y 1739 . Los límites cronológicos ${ }^{25}$, al menos en lo que se refiere al primer manuscrito, se situarian así entre 1728 y 1735 . Respecto a los otros tres, no hay ninguna indicación que pueda servir de referencia en el segundo y cuarto; en el tercero, aparece la cita del Diccionario de Autoridades a la que ya hemos aludido, lo que limitaría la fecha de redacción como mínimo a 1726 , pero no hay ningún otro dato orientativo.

El problema de la cronología relativa, así como de la relación interna entre los cuatro manuscritos presenta una complejidad que supera los límites de este artículo. Como hemos señalado, las ideas que se exponen en ellos son básicamente las mismas, y pueden completarse con las que aparecen en las Reflecciones y en las frecuentes alusiones a cuestiones ortográficas en su correspondencia.

Según el relato del propio Mayans tanto en cartas privadas como en algunas de sus obras publicadas ${ }^{26}$, Bordazar no llegó a ver su método escrito y elaboró su obra a partir de los datos que él le dio en una conversación sobre el tema. Bordazar, según estos testimonios, escribió una primera versión en la que recogía los datos ofrecidos de viva voz por don Gregorio y se la mostró. Para que pudiera completar su información, Mayans le prestó

24 Vid. supra, nota 17.

25 Cf. D. Azorín y E. Feliu, "Un manuscrito olvidado de D. Gregorio Mayans y Siscar: El Abecé Español”, Estudios de Lingüistica, Universidad de Alicante, 3, 198586, págs. 269-285. Basándose en la cita literal del "Discurso Proemial" y en la carta de Mayans a J. H. Valiente (23-I-1732) publicada en las Cartas morales, militares, civiles $y$ literarias de varios autores españoles (Valencia, 1773), los autores sitúan el momento de la redacción entre 1726 y 1732. Como hemos señalado, algunos datos indican que la obra, al menos en lo que respecta a su primer y principal manuscrito, no se redactó hasta 1728. Vid. también D. Azorín, "Don Gregorio Mayans y la polémica ortográfica en el siglo xvirI", Anales de Filología Hispánica, 3, 1987, págs. 107-120.

28 Encontramos alusiones a la polémica en muchas más cartas además de las inéditas que aquí aportamos y de las anteriormente publicadas. La mayor parte de la correspondencia de Mayans, cuyo volumen alcanza proporciones gigantescas, permanece inédita a pesar de la inestimable labor realizada por don Antonio Mestre, responsable de la edición de los ocho tomos del Epistolario y los cinco de las Obras Completas de Mayans aparecidos hasta el momento, así como de los principales estudios sobre la obra del erudito de Oliva. 
entonces algunos tratados ortográficos de otros autores, a partir de la lectura de los cuales Bordazar elaboró un sistema propio que se apartaba en algunos puntos del de su interlocutor. Además, Mayans escribió las cartas laudatorias que acompañaron las ediciones $\mathrm{y}$, según su propio testimonio corroborado por las alusiones de Bordazar en las cartas intercambiadas entre ambos, revisó la redacción tanto de la primera edición como de la "Apología" de la segunda, respetando siempre aquellas opiniones con las que no coincidía ${ }^{27}$. Fue también autor de la "Aprobación", que aparece firmada por el Dr. Tomás Navarro, según una anotación manuscrita de Juan Antonio Mayans en un volumen de la Ortografía de Bordazar que se conserva en el Fondo Serrano Morales (Biblioteca Municipal de Valencia) y que procede de la biblioteca de don Gregorio.

Como hemos señalado, Mayans se refiere a Bordazar en varias ocasiones en el Abecé, siempre dentro del primer manuscrito ${ }^{28}$, aludiendo de forma laudatoria a sus opiniones, coincidentes en unos casos y discrepantes en otros. También Bordazar nombra a Mayans de forma explícita en la "Apología", aduciendo su opinión como autoridad y señalando: "usa la mayor parte de mi Ortografía” ${ }^{29}$. Ya hemos señalado, por otra parte, que Mayans fue el

\footnotetext{
27 Mayans le prestó a Bordazar, entre otras, las ortografias de Correas y Alemán, como hemos señalado, y corrigió su estilo. Lo relata de esta forma en la $V$ ita (ed. cit., págs. 42-43): "Is cum a Maiansio petiisset vt suam Orthographiam Hispanam sibi exponeret, et ille annuisset; libenter eum audivit, et in scripta redegit quae ab eo acceperat, vsus tament iudicio et dicendi genere suo, quod, antea quam cum Maiansio communicaret, metaphoricum erat et floridum; postea vero purius maturiusque. Cumque libellum suum absolvisset, Aristarchi sui censurae se tradidit, qui, eiusdem argumenti libros aliquos Bordazari largiens, iussit vt a se paullo ante scripta cantraheret, et nova illa librorum doctrina magis illustraret: quod egregie praestitit Bordazar, in duabus aut tribus rebus a Maiansio dissentiens, adhaerens scriptoribus, quos ab eo acceperat, Mathaeo scilicet Alemano, Gundisalvo Correae, aliisque similibus." En carta al Barón de Schomberg (18-VII-1730) escribe Mayans refiriéndose a la Ortografía latina de Bordazar (Valencia, 1730): "Dicen que esta ortografía Latina no es tan buena como la Castellana, para la qual (la Castellana digo) le di yo materiales, i después la corregí" (Biblioteca Municipal de Valencia, caja 7.272-43, ms. 11.299). Vid. supra, nota 12.

${ }_{28}$ Las alusiones a Bordazar en el Abecé se encuentran, concretamente, en las páginas 23, 34, 39 у 62 .

29 "Apología", pág. 151. Bordazar no nombra a Mayans en el texto de la Ortografía Española, pero sí en la "Apología" en varias ocasiones. Don Gregorio revisó la redacción de la respuesta a Mañer, cuyo desarrollo puede seguirse en su correspondencia con el editor (BAHM, 2). En carta de Mayans al Barón de Schomberg (12-IX-1730) puede leerse: "Antonio Bordazar se halla ahora ocupado en responder a unas advertencias que ha hecho contra su ortografía D. Salvador Mañer. Se sacudirá mui bien según veo; pues Bordazar me embía todo lo que trabaja, i yo desde aquí le ayudo en lo que puedo" (BMV, caja 7.272-43, ms. 11.293)
} 
principal difusor de la obra de Bordazar cuando se publicó y siempre habló de ésta y de su autor en términos elogiosos.

El cotejo entre el sistema de Bordazar y el que Mayans expone tanto en los manuscritos del Abecé como en las Reflecciones y en sus cartas, debe mostrar hasta qué punto eran ciertas las afirmaciones que uno y otro hicieron en su momento.

Los dos defienden una ortografía de tipo fonológico o fonémico ${ }^{30}$ en la cual a cada sonido indivisible pronunciado en la lengua debe corresponder una única grafía ${ }^{31}$. Rechazan, pues, de forma clara el criterio etimologista que conserva grafías no correspondientes a la pronunciación actual, siguiendo la línea que dos siglos antes había iniciado Nebrija, y en la que se han situado la mayoría de nuestros ortógrafos ${ }^{32}$.

Ambos manifiestan la necesidad de poner orden en una materia donde reinaba la anarquía y defienden una ortografía racional, basada en el principio fonológico que hemos señalado anteriormente, ofrecido como regla única. Evitan, sin embargo, simplificaciones absolutas y propuestas excesivamente novedosas que fueran en contra del uso de las letras que era generalmente aceptado. Intentaron evitar así un rechazo total del sistema, como ocurrió en los casos de Gonzalo Correas y Mateo Alemán, aun a costa de ciertas concesiones al principio general ${ }^{3 \mathbf{s}}$.

so Como ha indicado Esteve Serrano, en los casos en que se promulga que cada grafía represente un sonido indivisible y diferenciado, más que de ortografía fonética cabría hablar de ortografía fonológica, ya que los autores "no pretenden reflejar todas las variedades de sonidos realizados y existentes en el habla, sino aquellas invariantes que poseen valor distintivo" (A. Esteve Serrano, op. cit., pág. 48). Cf. J. Mosterín, La ortografía fonémica del español, Madrid, Alianza Universidad, 1981, pág. 34: "El principio fonémico exige que haya una letra y sólo una para representar cada fonema de la lengua y que un fonema y sólo uno corresponde a cada letra."

31 "La pronunciación asignada a cada uno de los elementos propuestos, es sabida, común e irrefragable: Luego la Ortografia en que se usare constantemente de estos elementos correspondientes a la articulacion, será recta, racional, e irrefragable; $i$ tendrá regla cierta, lei justa, i punto fijo." Bordazar, Ortografía Española, pág. 12.

"Que la escritura deva representar a la pronunciación es regla de todos los ortógrafos, griegos, latinos, italianos, $i$ aun franceses, $i$ de todas las naciones que han tenido, i tienen letras: i assí lo practican los mismos que lo niegan." Mayans a Diego de Arredondo, 17-II-1753; BAHM, 116.

32 Cf. Esteve Serrano, op. cit. Vid. también A. Rosenblat, "Las ideas ortográficas de Bello", prólogo al volumen V de los Estudios Gramaticales de A. Bello, Caracas, Comisión editora de las Obras Completas de A. Bello, 1951.

s3 Tras haberse referido a los fracasos de los sistemas de Mateo Alemán y Gonzalo Correas a pesar de su coherencia, señala Mayans: "Cargando yo la consideración sobre esto, vine a pensar que para formar un sistema que merezca ser bien admitido, conviene primeramente desechar las opiniones que, aviendo sido propuestas uno o dos siglos ha, nunca han sido admitidas, ni de todos, ni de pocos; abrazando solamente las que han 
Examinaremos a continuación las semejanzas y diferencias más sobresalientes entre los sistemas de ambos autores.

El abecedario que Bordazar propone en su obra consta de 28 grafías correspondientes a 27 articulaciones distintas, aunque indica que hay 30 elementos, teniendo en cuenta, probablemente, que algunas grafias representan dos potestades ${ }^{34}$. Aparecen LL, RR, $\widehat{\mathrm{N}}$ como grafías independientes correspondientes a articulaciones diferenciadas, pero no recoge la $\mathrm{K}$. Sí considera como letra la $\mathrm{H}$, aunque indicando que se trata de una letra "en duda" ${ }^{5}$.

El abecedario que Mayans propone en las Reflecciones tiene 26 letras, ya que no cuenta en la enumeración la $\mathrm{H}$, caracterizada como "nota de aspiración", ni tampoco la $\mathrm{K}^{36}$. Sin embargo, la $\mathrm{H}$ se considera como letra en los tres manuscritos del Abecé, aunque siempre indicando su peculiaridad en cuanto que no representa propiamente un sonido indivisible. $\mathrm{La} \mathrm{K}$ aparece como letra en el primer manuscrito del Abecé, aunque explica el autor que es superflua para indicar el sonido $c a$, suficientemente representado con las grafías $\mathrm{C}$ y $\mathrm{QU}{ }^{37}$; sólo el hecho de que aparezca en algunos nombres de origen latino hace que deba conocerse para su correcta lectura, y por esto la mantiene Mayans, a pesar de que acaba la explicación de esta letra indicando que es de parecer que se omita en el abecedario español. En el tercer manuscrito, la $\mathrm{K}$ no aparece en la enumeración inicial de las letras españolas. Indica más adelante en este mismo texto que es letra griega, no española, ni latina, y que algunas voces extranjeras "malamente escritas por los nuestros" hacen necesario su conocimiento ${ }^{88}$.

$\mathrm{La}$ distribución de grafías resulta, pues, básicamente coincidente. Desechan ambos la Ç y la X con valor de jota, y fijan la J y QU como grafías "su-

\footnotetext{
sido aprovadas de toda la nación." Mayans a José Hipólito Valiente (23-I-1732). Vid. supra, nota 19.

34 Ortografía Española, pág. 10. La distinción clásica entre "nomen", "figura" y "potestas" como "accidentes" de las letras aparece claramente en Mayans y en Bordazar, como en Nebrija. La relación entre los tres elementos debería ser única, pero el hecho es que los procesos de corrupción han hecho que algunas figuras tengan dos "potestas", lo que plantea problemas respecto a la posibilidad de hablar de una o de dos letras, según atendamos preferentemente a la "figura" o a la "potestas". Vid. Amado Alonso, "Noticias de Nebrija sobre pronunciación española", Nueva Revista de Filología Hispánica, 1949, 1, pág. 7. En cuanto al término "elemento" aparece ya en Dionisio de Tracia y alude a la fragmentación de los sonidos de la voz humana. $V$ id. $\mathrm{R}$. $\mathbf{H}$. Robins, Breve Historia de la lingüistica, pág. 41. En este sentido debemos entender "elementos" como equivalente a "articulaciones", que serían, efectivamente, 30.

ss Ortografía Española, págs, 21-23; “Apología”, pág. 170.

36 Reflecciones, págs. 64 y 82-84.

37 Abecé, primer manuscrito, pág. 27.

38 Abecé, tercer manuscrito, pág. [8].
} 
pletorias" ${ }^{39}$ de G y C para completar sus combinaciones con todas las vocales. Ambos desechan las grafías latinizantes del tipo $\mathrm{TH}, \mathrm{PH}$, así como la duplicación de consonantes sin valor fonético, etc. En el caso de Bordazar, este rechazo es radical y prácticamente $\sin$ excepciones ${ }^{40}$, mientras que Mayans las admite en su Abecé, aunque sólo en casos muy aislados ${ }^{41}$.

La coincidencia más espectacular, por lo clara, se da en las descripciones articulatorias de las pronunciaciones correspondientes a cada una de las letras. Dichas descripciones se repiten prácticamente al pie de la letra en la obra de Bordazar y en los tres manuscritos del Abecé mayansiano ${ }^{42}$.

La principal dificultad para explicar este hecho radica en el desconocimiento de la fecha exacta de composición del Abecé. Los testimonios personales de Mayans respecto a su papel en la elaboración de la obra de Bordazar, a los que nos hemos referido más arriba, tampoco nos permiten aventurar una solución definitiva. Resulta difícil afirmar que tales descripciones fueron proporcionadas por Mayans, o, por el contrario, que éste las recogió de Bordazar al redactar su tratado, suponiendo que sea de fecha posterior. En todo caso, la literalidad de las coincidencias parece excluir la simple recogida de unas opiniones expuestas de forma oral, tal como Mayans mantiene en su relato de los hechos. Por otra parte, desconocemos cuáles fueron las posibles correcciones o aportaciones de don Gregorio en la revisión que, según su propio testimonio ${ }^{43}$, realizó tanto de su versión inicial como de la

38 El concepto de grafías supletorias procede de Nebrija y de su concepto de la letra como nomen-figura-potestas en correspondencia unívoca. Vid. supra, nota 34.

to Sólo admite la doble S por razón de un uso generalizado de esta grafía etimológica. Ortografía Española, pág. 42.

41 En el primer manuscrito (pág. 75) admite las grafías $\mathrm{TH}, \mathrm{CH}, \mathrm{RH}$ en algunos casos: "Las consonantes que toman aspiración en voces peregrinas españolizadas son tres, R. C. T. como se ve en Rhetórica, Christos, Matheo."

42 Ofrecemos sólo dos casos a modo de ejemplo: "G. Esta letra, hiriendo a las vocales imediatamente, tiene, como la $c$, los dos oficios propios, que nadie duda. El principal, a que llamamos ga, es el que suena encorvándose la lengua para herir la raíz del paladar, dando la respiración más adentro que con la ca" (Bordazar, Ortografía Española, pág. 20). "Sabemos que ai en la lengua española el sonido consonante Ga, que se pronuncia encovándose la lengua para herir la raíz del paladar dando la respiración más adentro que con la Ca" (Mayans, Abecé, primer manuscrito, págs. 18-19).

"L. Ésta se forma, hiriendo la lengua en el paladar acia la metad con la parte baja de ella, para lo cual se arquea un tanto acia dentro, arrojándose por sus lados la respiración" (Bordazar, Ortografía Española, pág. 27). "Es cosa averiguada, que la lengua española tiene el sonido consonante Le, que se forma hiriendo la lengua en el paladar, acia la mitad con la parte baja de ella, para lo qual se arquea acia dentro arrojándose por sus lados la respiración" (Mayans, Abecé, primer manuscrito, pág. 28).

43 Bordazar a Mayans (2-VIII-1730): "Mi idea es reimprimir la Ortografía, Segunda impression, añadida una defensa i satisfación a las instancias vulgares; no obstante vea U. M. si le parece otra: U. M. lo mire, i lo remire de arriba a bajo, borrando 
que el editor hizo tras la lectura de los tratados a la que ya nos hemos referido.

A pesar de estas coincidencias, que hubieran proporcionado argumentos a los que afirmaron que la obra de Bordazar era en realidad de Mayans, no cabe duda de que el editor mantenía posiciones diferenciadas respecto a ciertas grafías especialmente problemáticas, como el propio Mayans indicó en su momento.

Los casos más claros y beligerantes de discrepancia, aunque no los únicos, se dan en las letras $\mathrm{H}$ y $Q U$, y especialmente en esta última, como señaló don Gregorio en la carta que dirigió en 1732 a otro ortógrafo, José Hipólito Valiente *4.

Tanto Mayans como Bordazar proponen para el sonido velar oclusivo sordo las grafías $\mathrm{C}$ y QU, esta última como "suplidora" con las vocales E, $\mathrm{I}$, cuya pronunciación original con $\mathrm{C}$ se ha corrompido ${ }^{45}$. Se consigue asi una distribución complementaria que, seguida sin excepción, evita toda ambigüedad. Sin embargo, Mayans acepta que la grafia $Q U$ represente el sonido $c u$ en algunos vocablos como quando, qual, qüestión, etc. En todos los casos señalados, el uso se corresponde con grafías etimológicas; pero don Gregorio, que rechaza abierta y repetidamente la etimología como criterio decisivo en la ortografía, no reconoce el origen como razón de uso de la grafía QU en estas palabras. Por el contrario, afirma que la pronunciación representada por QU es "más fuerte" que la de $C^{46}$. No es ésta una opinión que se repita en la historia de nuestra ortografía. Sólo Valdés alude a esta diferencia ${ }^{47}$, sin que ningún otro tratadista la recoja en los siglos xvi y

i mudando hasta que quede a satisfación de U. M. puesto que U. M. es mi oráculo, i no tengo otro en el mundo de quien confiar" (BAHM, 2).

4 "Aviendo yo propuesto mi sistema a Antonio Bordazar, impressor de mucho juicio i diligendia, se hizo capaz de él; formó una delineación, i como no es fácil que uno se conforme en todo con otro, en tal opinión se apartó de mí, singularmente en el uso de la C. Motivo que ha dado ocasión al vulgo indiscreto de confundir la verdad." Vid. supra, nota 27.

4 Mayans, Abecé, primer manuscrito, págs. 15-18, 31-35; segundo manuscrito, páginas [6]-[9]; tercer manuscrito, págs. [3]-[4]; Reflecciones, págs. 60-66. Bordazar, Ortografía Española, págs. 15-18 y 30-31.

46 "Si acaso se ha de herir a la U, con suavidad úsese de C, como en cuaderno, cuerpo; si con mayor fuerza úsese de Q., como en qual, quando. Esta Regla se conforma admirablemente con la etimología, sin atenderla." Abecé, primer manuscrito, pág. 35.

47 "Los [vocablos] que se an de scrivir con $q$, tienen la pronunciación más hueca que los que se han de scrivir con $c$, los quales la tienen mucho más blanda; sé que más vehemencia pongo yo quando dogo quaresma que no quando cuello" (Juan de Valdés, Dí́logo de la lengua, edic. Antonio Comas, Barcelona, Bruguera, 1972, pág. 100). Gregorio Salvador se refiere a esto que llama "fantasías valdesianas" señalando que no prosperaron (Sobre la letra " $q$ ". Discurso de recepción en la Real Academia Espafiola, Madrid, 1987, págs. 21-22). 
xvir, según ha señalado Esteve Serrano ${ }^{48}$. Mayans no acude al Diálogo para autorizar su opinión, ni en el Abecé ni en las Reflecciones ${ }^{49}$, sino a Quintiliano, que al parecer había señalado tal distinción para el latín ${ }^{50}$. Bordazar rechaza claramente esta mayor fuerza en la pronunciación de la QU y defiende el uso sin excepciones de la grafía $C$ para la combinación con la vocal $U^{51}$. Esteve Serrano, sorprendido por esta aclaración relativa a una cuestión que aparentemente nadie había puesto en duda en dos siglos, supone que quizá Bordazar respondiera a algún tratadista de segundo orden. Más allá de los juicios de valor, parece evidente que este tratadista era Mayans, quien expuso ampliamente esta propuesta en el Abecé y la recogió al publicar sus Reflecciones, lo que provocó de nuevo el reproche de Bordazar en una carta inédita ${ }^{62}$.

La segunda discrepancia clara, aunque tampoco en este caso el impresor nombre a Mayans, aparece en el tratamiento de la H. En el Abecé, don Gregorio señala tres valores para esta grafía: dar mayor fuerza a las vocales que la siguen, representar junto con la $\mathrm{C}$ la pronunciación che e indicar la aspiración en algunos casos ${ }^{53}$. Bordazar parece acabar aceptando estos valores, sobre todo si atendemos a cierta afirmación de la "Apología" ${ }^{54}$. Sin em-

48 Op. cit., pág. 362 : "No hemos encontrado entre los ortógrafos consultados de los siglos XVI y XVII ningún testimonio que coincida con la afirmación de Valdés."

49 Mayans no conoció el Diálogo, entonces de desconocido autor, hasta que éste fue enviado a Nasarre desde Aragón con otras obras. Mayans le pidió permiso para editarlo junto con otros escritos sobre el tema y elaboró sus Orígenes. Probablemente, pues, no lo conocía cuando escribió el Abecé, aunque sí en el momento de publicar sus Reflecciones, donde tampoco lo cita para defender este uso.

so "Prevaleció en los latinos la introducción de la Q. Letra que según Velio Longo, i Marciano Capela equivale a $\mathrm{Cu}$. I según lo que dijo Quintiliano de su dureza, hería con alguna mayor fuerza que la C". Abecé, primer manuscrito, pág. 32.

51 "La cu por sí sola no es letra, sino parte de una letra, o elemento, que se compone con la $u, Q U$ : cuya articulación en nada se diferencia de la c con huelgo, por más que algunos quieran atribuirle distinta i mayor corpulencia." Ortografía Española, página 30 .

52 Bordazar a Mayans (23-III-1735): "Lo que he sentido mal en las reflexiones, o reflecciones, pero no se me sienta reflecciones, es del lunar de la q, a cuyo solo uso en que, qui, U. M. no quiere deferir juzgándose de más delicado oído que el mismo Lebrija que la quita fuera de esse empleo: verdaderamente ai tanto que decir contra esse dictamen que más quiero callar que decir poco; puede ser que cuando V. M. saque a luz su Abecé dege U. M. la cosa más clara o convincente" (BAHM, 2).

53 Abecé, primer manuscrito, págs. 21-26; tercer manuscrito, págs. [4]-[6].

s. "Yo la propongo, i uso, por nota que da vigor a la pronunciación en he, has, ha, \&c. i por señal de aspiración en $a h$, ah intergeciones: assí mismo la uso con la Cartilla como carácter que unido a la $c$, esto es $c h$. compone una letra, o articulación: i por esso está dos veces en los elementos, como aspiración, i como media letra." "Apología", pág. 170 . 
bargo, en el texto de la Ortografía Española expone claramente sus dudas respecto a la mayor fuerza que supuestamente la $\mathrm{H}$ proporciona a las vocales. Indica que esto vendría a ser algo semejante a un "medio acento" o a una aspiración que él afirma no percibir. Por todo ello la describe como pura "divisa etimológica" y la juzga ociosa salvo en el caso de la che. No la elimina, sin embargo, del alfabeto por no ir contra el uso común ${ }^{55}$. Mayans, por el contrario, sí percibe, según dice, esa mayor fuerza que la $\mathrm{H}$ proporciona a las vocales a las que se antepone, lo que le sirve para justificar su mantenimiento sin apelar al pura razón de etimología. Hace alusión, sin embargo, a la opinión de Bordazar en una nota marginal al primer manuscrito del Abecé, indicando que el impresor le ha manifestado en algunas ocasiones que no percibe el particular valor fonológico de esta grafía ${ }^{66}$.

En un tercer caso observa Bordazar una razón puramente etimológica donde Mayans mantiene una diferencia de pronunciación. Se trata del uso de la grafía doble SS, que ambos admiten en ciertos casos (algunos tiempos verbales, superlativos con -ísimo, etc.) ${ }^{57}$. Mayans no alude a esta grafía en el Abecí, donde sólo trata de la $\mathrm{S}$ simple, pero sí en cierta carta inédita donde defiende la duplicación basándose en una diferencia de pronunciación cuya peculiaridad, sin embargo, no llega a aclarar ${ }^{58}$. Por el contrario, Bordazar indica claramente que se trata de grafías etimológicas que el uso ha generalizado, pero que no responden a una diferencia real con el sonido representado por la S simple ${ }^{6 \theta}$.

ss "Síguese pues, que [la $h$ ] sólo es divisa etimológica con que se prohijan los escritos, aunque no las voces, a sus patrios lares: en lo cual me sugeto al uso común, por no ser tan importantes su exclusión." Ortografía Española, pág. 23.

ธь "I cuando sigo el origen no es meramente por seguirlo, sino por parecerme que el derivado conserva en la pronunciación aquella mayor fuerza del primitivo. Digo que assi me parece aunque Antonio Bordazar me ha dicho algunas veces, que juzga que es imaginación. Quizá sería del mismo sentir Antonio de Lebrija, pues deshechó la H., escriviendo, ueso." Abecé, primer manuscrito, pág. 23.

57 "Ninguna consonante se duplica (excepto la $s$, en superlativos, en optativos, i en otras voces en que tiene possessión).” Bordazar, Ortografía Española, pág. 42.

58 "Algunos amantes de la novedad caprichosa han introducido una cosa mui agradable a los impressores, i es, la omissión de una letra que siempre se ha duplicado en la pronunciación, i en la escritura [...] porque es menester distinguir ámase del presente de indicativo con el recíproco se enclítico de amasse del pretérito del modo sugen tivo: el uno con una s; el otro con dos." Mayans a Antonio Sancha, 15-IV-1777 (BMV, caja 7.272-43, ms. 11.263).

sө Ortografía Española, pág. 33: “Acostumbrase duplicar en los tiempos de pretérito imprefecto, i sujuntivo, como bolviesse, viniesse, fuesse, a diferencia fuèse, esto es, se fuc; i en los superlativos amantissimo, hermosissimo, ilustrissimo, \&c. por la derivación, o imitación Latina. Pero a mi ver, ni se pronuncia doblada, ni se devia escrivir, porque la suavidad i licuecencia Castellana, no admite bien consonante doble unisona en la pronunciación." 
Otro caso de discrepancia que no aparece claramente en los respectivos tratados, pero sí en la correspondencia privada entre ambos autores, se refiere al uso de B y V. Tanto Mayans como Bordazar señalan una diferente pronunciación; caracterizan la $\mathrm{B}$ como bilabial y la $\mathrm{V}$ como labiodental y apelan a la pronunciación de los valencianos como modelo inequivoco. Sin embargo, esta diferencia teórica, aparentemente clara para los dos, no lo parece tanto cuando en algunos vocablos, como prueba y sus derivados, ambos discrepan defendiendo vivamente su propia opinión con idénticas razones: la pronunciación valenciana y el uso común ${ }^{60}$. La conclusión lógica es que ni una ni otro eran, evidentemente, unívocos.

Nos hemos referido hasta aqui más a un cotejo de ideas que de obras, y esto por una razón clara. En el caso de Bordazar, nos encontramos con una Ortografía publicada, completa, en la que observamos la formulación definitiva de su sistema. Por el contrario, en el caso de Mayans nos enfrentamos a un corpus en gran medida disperso, aunque, finalmente, bastante coherente en su contenido. Contamos únicamente con una obra publicada sobre el tema, las Reflecciones, que podríamos tomar como expresión definitiva de sus ideas, pero que no es más que un resumen de lo espuesto en el $A b e c e^{61}$. Este último, además, aparece como una obra problemática en cuanto a su elaboración, ya que, según el testimonio de su autor, fue escrita en fecha muy temprana, sin que, al parecer, tal manuscrito se haya conservado. Por otra parte. el libro que encontramos encuadernado por el mismo Mayans con este nombre, resulta constar de cuatro manuscritos, aunque sólo el primero reciba propiamente en su encabezamiento este título y sea el único que parece contener una obra acabada. Para completar este confuso panorama, esta obra, que deberíamos considerar el sistema ortográfico propio al que Mayans remitirá durante toda su vida, estaría ya elaborada, según su autor, cuando Bordazar escribió la suya. Ya hemos señalado, sin embargo, que algunos da-

50 Mayans a Asensio Sales (22-IX-1742): "Ahora que hablo de Aprovación, Vmd. haga que esta palabra se escriva con $\mathrm{V}$, i no con $\mathrm{B}$, contra la opinión de nuestro amigo Bordazar, pues assi lo escriven los valencianos en su lengua, que es la que da lei en la V a los castellanos" (BAHM, 130).

Bordazar a Mayans (10-X-1742): "Lo que llevo mui mal es que U. M. ha dado aora en trocar las bb i vv, dejándose llevar (lo que jamás se ha hecho) del ejemplo viciado común de Castilla, siendo assí que los valenciamos hemos sido, i somos los oráculos de essas dos letras; i U. M. ha escrito millares de veces Aprobación, i no Aprovación, con otras muchas que no se me ocurren: vea U. M. mi ortografía i defiera U. M. a ella en esto" (BAHM, 2).

61 En gran número de las alusiones a las Reflecciones que Mayans realiza en cartas y obras, éstas van unidas al deseo de publicar su Abecé que "tiene más gran saber de los que muchos piensan". Mayans a J. Marín, 1-III-1760; BAHM, 159. 
tos apuntan a una redacción posterior a la obra del impresor, al menos en lo que respecta a este manuscrito principal.

A pesar de estas dificultades, podemos establecer algunas conclusiones, sin que éstas pretendan ser definitivas, ya que su valor dependerá de lo que futuras investigaciones puedan aportar sobre la obra de ambos autores.

Como ya hemos señalado, Mayans indicó que entre su obra y la de Bordazar había diferencias en el uso de algunas grafias, como la QU. El cotejo entre los dos sistemas demuestra que existian estas discrepancias, que eran la prueba que Mayans alegaba contra los que le adjudicaban la autoría de la obra de Bordazar. Este hecho, asi como los restantes testimonios de ambos autores en una correspondencia que permanece inédita en su práctica totalidad, pueden considerarse suficientes para aceptar que, efectivamente, Bordazar fue el autor de la Ortografía que apareció con su nombre.

Parece también evidente, sin embargo, según estos mismos testimonios, que Mayans dio pie a la elaboración de la obra, y que el desconocido sistema recogido en principio por Bordazar fue el suyo, aunque posteriores lecturas, facilitadas también por don Gregorio, le llevaron a opiniones discrepantes. Además, el intercambio epistolar demuestra que el impresor sujetó a la censura de Mayans tanto la redacción de la Ortografia como la de la "Apologia" que aparece en la segunda edición de la misma. Es más, al estallar la polémica Bordazar no adoptó una posición beligerante, sino que manifestó en su correspondencia con Mayans, al que admiraba profundamente, sentirse halagado por tal sospecha, refiriéndose a la obra en litigio como "nuestra Ortografía"

En cuanto a las coincidencias literales, no podemos afirmar, con los datos de que disponemos, quién elaboró realmente las descripciones articulatorias que se repiten en ambos tratados. Según su propio testimonio, Mayans respetó, al revisar la obra de Bordazar, aquellos puntos en los que discrepaba ; pero nada dice sobre su intervención en la redacción definitiva de aquellos en los que ambos autores coincidian. Por otra parte, puede resultar significativo que sea precisamente en las descripciones articulatorias donde las coincidencias, que también se producen en otros momentos y en el uso de la mayoria de las grafías, sean literales ${ }^{63}$. Mayans podría no haber dado impor-

62 Bordazar a Mayans (14-VII-1728): “De nuestra Ortografía legítima i putativa a medias, no he oído hablar mal; i si no, que se atrevan" (BAHM, 2). Vid. supra, nota 8.

6s Las descripciones presentan a veces ligerísimas variaciones, como puede observarse en la siguiente (los subrayados de las citas son nuestros):

"F. Se articula con respiración apremiada de los dientes superiores sobre el labio inferior." Bordazar, Ortografía Española, pág. 19.

"El sonido consonante fe es español, se articula con respiración apremiada de los dientes superiores con el labio inferior." Mayans, Abecé, pág. 18. 
tancia a su aportación personal en un aspecto casi puramente "técnico", que no se consideraría fundamental en un tratado en el que lo que importaba era la fijación y distribución de las grafías correspondientes a unos sonidos conocidos por todos ${ }^{64}$. Pero no podemos asegurar que tales descripciones no fueran obra de Bordazar, o incluso de ambos en una medida que desconocemos.

La polémica no favoreció, sin duda, la salida a la luz de datos que podrían ayudar a resolver esta cuestión. Como hemos señalado, Mayans señaló con algún detalle las discrepancias que demostraban la autoría de Bordazar; pero nada indicó sobre aportaciones personales concretas que hubieran dado argumentos a sus oponentes.

Resulta sorprendente, sin embargo, que, si el manuscrito principal del Abecé fue redactado, como parece, después de la obra del impresor, Mayans estuviera dispuesto a publicarlo con las coincidencias literales a las que nos referimos, $y$ sobre todo después de la polémica. La única explicación lógica, finalmente, podría encontrarse en el estado de preparación de los manuscritos conservados, ninguno de los cuales parece ser una versión definitiva destinada a su publicación ${ }^{65}$. Posiblemente, el temor de que se produjeran comparaciones a la búsqueda malintencionada de estas coincidencias y el hecho de discrepar con instituciones protegidas por el poder, como la Real Academia, frenaran de hecho esta publicación, según se deduce de algunas alusiones en sus cartas ${ }^{68}$.

En todo caso, y a modo de conclusión, puede observarse en las opiniones discrepantes de Bordazar una posición personal, razonada y razonable, precisamente en aquellos puntos en que el sistema de Mayans se aleja del principio general de reflejar la pronunciación actual para acatar, con más o menos justificaciones, usos de grafías que se basaban en criterios de autoridad,

Hay diferencias mayores en letras como la $\mathrm{R}, \mathrm{y}$, como ya se ha señalado, en los casos de discrepancias en cuanto al uso; pero, en su mayor parte, las coincidencias son literales. Vid. supra, nota 42.

64 Es el caso de las vocales, de las que no se ofrece ninguna descripción articulatoria ni en el primer ni el tercer manuscrito, ya que considera que no tienen ninguna dificultad para el hablante salvo en el caso de los usos de la I y U respecto a Y, V.

65 Varios detalles en los manuscritos hacen ver que no estaban preparados para la edición. En el caso del primero, la existencia de citas incompletas y datos en blanco que no se completan. En los otros tres, su mismo carácter fragmentario.

f6 Mayans a Diego de Arredondo (10-II-1753): "Por último, mi modo de escrivir se funda en la Cartilla, que todos leen de un mismo modo, i es inequivocable, pues todos leen aquello mismo que deven pronunciar. Esto pedía viva voz. $\mathrm{He}$ convencido a todos los que me han oído sobre este asunto, sobre el qual tengo escrito un libro de gran trabajo, i que dará regla a la Ortografía, pero he suspendido publicarle por mis contradictores" (BAHM, 116). 
librescos o puramente etimológicos ${ }^{6 \tau}$. Por el contrario, Bordazar, con espíritu crítico y basándose en lo que más que probablemente era la pronunciación real, negó las aventuradas ideas de Mayans sobre los sonidos diferenciados de grafías como $\mathrm{QU}$ o $\mathrm{H}$, siguiendo lo que consideraba cierto por encima del respeto indudable que le merecia la figura de don Gregorio, a cuya censura sometió su trabajo, y cuyas instrucciones siguió con devota obediencia ${ }^{68}$.

Mayans revisó muy de cerca la redacción tanto de la Ortografía de Bordazar como de la "Apología". Probablemente hizo aportaciones que hoy desconocemos, entre las que podrian estar las descripciones articulatorias; pero, finalmente, tras las lecturas que le facilitó don Gregorio, parece que Bordazar expuso su propio sistema ${ }^{* 9}$, en algunos casos más coherente con el principio fonetista que el del propio Mayans.

67 Bordazar describe la Ortografía como "una Ciencia", que, por falta de reforma, "dejando de serlo assí, se pervierte en la irregularidad”. Ortografia Española, pág. 3.

68 Por deseo de don Gregorio, Bordazar comenzó una obra tan inmensa como el Diccionario Facultativo, que quedó incompleto con su muerte en 1744. Este manuscrito, como los demás de Bordazar, fue comprado por Mayans, y actualmente se conserva inédito. Entre estos manuscritos no se encuentra el de la Ortografía Española. Vid. Vicente Ferrán Salvador, "Antonio Bordazar de Artazu. El impresor erudito", Boletín de la Sociedad Castellonense de Cultura, LI, 1964, págs. 119-147.

69 Bordazar a Mayans (23-III-1735): "Ciertamente me he alegrado, i aun envanecido de ver la Ortografía de Lebrija que U. M. ha sacado a luz i reflexionado delineándose en ella mi sistema; pues he tenido la fortuna de soñar una verdad, i tener un hallazgo que pocos creerán que no fue hurto" (BAHM, 2). 